\title{
Potential energy surfaces for small alcohol dimers I: Methanol and ethanol
}

Richard L. Rowley

rowley@byu.edu

Tapani A. Pakkanen

Christopher M. Tracy

Follow this and additional works at: https://scholarsarchive.byu.edu/facpub

Part of the Chemical Engineering Commons

\section{Original Publication Citation}

Rowley, Richard L., Christopher M. Tracy, and Tapani A. Pakkanen. "Potential energy surfaces for small alcohol dimers I: Methanol and ethanol." The Journal of Chemical Physics 125 (26)

\section{BYU ScholarsArchive Citation}

Rowley, Richard L.; Pakkanen, Tapani A.; and Tracy, Christopher M., "Potential energy surfaces for small alcohol dimers I: Methanol and ethanol" (2006). Faculty Publications. 287.

https://scholarsarchive.byu.edu/facpub/287 


\title{
Potential energy surfaces for small alcohol dimers I: Methanol and ethanol
}

\author{
Richard L. Rowley ${ }^{\text {a) }}$ and Christopher M. Tracy \\ Department of Chemical Engineering, Brigham Young University, Provo, Utah 84602
}

Tapani A. Pakkanen

Department of Chemistry, University of Joensuu, FIN-80101 Joensuu, Finland

(Received 28 July 2006; accepted 24 August 2006; published online 16 October 2006)

\begin{abstract}
Potential energy landscapes for homogeneous dimers of methanol and ethanol were calculated using counterpoise $(\mathrm{CP})$ corrected energies at the MP2/6-311+G(2df,2pd) level. The landscapes were sampled at approximately 15 dimer separation distances for different relative monomer geometries, or routes, given in terms of a relative monomer yaw, pitch, and roll and the spherical angles between the monomer centers (taken as the $\mathrm{C}$ atom attached to the $\mathrm{O}$ ). The 19 different routes studied for methanol and the 22 routes examined for ethanol include $607 \mathrm{CP}$ corrected energies. Both landscapes can be adequately represented by site-site, pairwise-additive models, suitable for use in molecular simulations. A modified Morse potential is used for the individual pair interactions either with or without point charges to represent the monomer charge distribution. A slightly better representation of the methanol landscape is obtained using point charges, while the potential energy landscape of ethanol is slightly better without point charges. This latter representation may be computationally advantageous for molecular simulations because it avoids difficulties associated with long-range effects of point-charge-type models. () 2006 American Institute of Physics. [DOI: $10.1063 / 1.2356467]$
\end{abstract}

\section{INTRODUCTION}

Knowledge of intermolecular interaction potentials is crucial in both understanding and predicting condensedmatter thermophysical properties. For example, the reliability of the model used to represent the intermolecular potential primarily determines the effectiveness and accuracy of properties obtained from Monte Carlo simulations. Similarly, molecular dynamics simulations generally obtain intermolecular forces from the potential model, and again the quality of the results is primarily dependent upon the efficacy of the model potential. Accurate determination of intermolecular interaction potentials is therefore of central importance in modeling thermophysical properties of fluids.

The potential model used in molecular simulations, either Monte Carlo or molecular dynamics, is often a sum of simple pairwise-additive site-site potentials with each pair interaction represented by a simple, usually spherically symmetric, analytical expression. If the parameters in these models are regressed from experimental data, the empirical parameters can compensate for model inadequacies, such as three-body effects or oversimplification in model form. Direct measurement of intermolecular interactions is still problematic, ${ }^{1}$ but $a b$ initio calculations offer a convenient method for determination of the complex intermolecular potential surface or landscape of molecular pairs and clusters of molecules. ${ }^{2}$ While these calculated potentials are not dependent on an analytical model, they are dependent upon the level of theory and size of the basis set used in representing the wave function. The Hartree-Fock (HF) self-consistent

${ }^{a)}$ Electronic mail: rowley@byu.edu theory includes the exchange-repulsion interactions that dominate the strong repulsions of overlapping electron densities, but post-HF methods such as Moller-Plesset (MP) perturbation theory and coupled cluster (CC) theory are generally required to calculate the attraction due to dispersion. Dispersion arises from the nonlocal, simultaneous electron correlation between the nonbonded species. ${ }^{3,4}$ Reasonably large basis sets with multiple polarization functions are generally required for accurate determination of dimer energies. At least part of the reason for this is that the Gaussian functions commonly used by computational chemistry programs to constitute basis sets are local functions. ${ }^{5}$ Dimer potential energy landscapes, when computed with appropriate $a b$ initio methods, can be used directly in Monte Carlo simulations and molecular modeling, or they can be further parametrized in terms of analytical equations or site-site interaction models. Models obtained from the dimer potential energy surface are true pair potentials and may need multibody corrections for accurate simulations at high densities.

$A b$ initio dimer potential energy surfaces of atomic inert gas molecule with either another inert gas molecule ${ }^{6-11}$ or some other small, nonpolar ${ }^{12-15}$ or polar ${ }^{16,17}$ molecule have been extensively studied. The lower dimensionality of the system (requiring only an interatomic separation distance as an independent variable for an atomic pair of inert gas molecules) and the ability to study level of theory and basis-size dependence on small systems are ideal for developing appropriate methodologies. The techniques developed have been extensively used to produce more complex potential energy landscapes and to study and characterize the interactions between molecules. For example, ab initio dimer potential 
energies and/or surfaces have been developed for diatomic species, ${ }^{18,19}$ methane, ${ }^{2,20-25}$ and small, nonpolar organic molecules. ${ }^{26-36}$ Studies of molecular dimer potential energy surfaces for polar molecules ${ }^{37-40}$ and for hydrogen-bonding pairs $^{41-46}$ have also been recently conducted. Much larger dimer pairs have also received recent attention. ${ }^{4-50}$

Appropriate procedures and limitations for the calculation of accurate pair potential surfaces have arisen from these studies. Pair potential energies are usually calculated for the supermolecule, and counterpoise (CP) corrections are required to minimize basis set superposition error (BSSE). ${ }^{6,12,20}$ Several studies found that the effects of electron correlation beyond MP2 were not large..$^{2,24,27,38}$ Density functional theory (DFT) calculations generally do not adequately represent nonbonded dispersion energies, ${ }^{24,27,51}$ but progress on improving the DFT calculations for these purposes is being made. ${ }^{9}$ The studies mentioned above and others like them have shown that accurate potential energy surfaces can be obtained from calculations using MP2 and higher levels of theory with large basis sets containing multiple polarization functions.

Convenient representation of the pair intermolecular potential energy landscape for multiatomic molecules is difficult given the high dimensionality of the system for the various relative orientations of the monomers. Direct use of the $a b$ initio potential landscape data in Monte Carlo simulations may be possible with an appropriate interpolation scheme if adequate coverage of the surface features has been achieved, but generally, the landscapes have been regressed in terms of various site-site interaction models. ${ }^{38,41,52-56}$ In fact, the development of model potentials from $a b$ initio calculated landscapes has become an important aspect of molecular simulation work.

Often $a b$ initio potentials are validated by comparing thermodynamic and structural properties obtained from molecular simulations using models regressed from the $a b$ initio potential surface. ${ }^{52,55,57,58}$ Generally simulated properties obtained using these $a b$ initio-derived pair potential models compare favorably with results obtained using empirically parametrized potentials such as the optimized potentials for liquid simulation (OPLS) model. ${ }^{38,59}$ Even more rigorous tests generally exhibit good agreement between experiment and simulation results obtained using models derived from quality $a b$ initio potential surfaces. For example, the vaporliquid dome for noble gases and their mixtures ${ }^{10}$ and for acetylene $^{54}$ generated using Gibbs ensemble Monte Carlo simulations and $a b$ initio-derived potential models were in excellent agreement with experiment.

Our previous studies of potential energy landscapes ${ }^{2,32-36}$ focused primarily on hydrocarbon dimers without strong directional interactions. The resultant potential energy landscapes were parametrized with a pairwise summation of atom-atom potentials each represented with a modified Morse potential model. The Morse parameters obtained for the $\mathrm{C}-\mathrm{C}, \mathrm{C}-\mathrm{H}$, and $\mathrm{H}-\mathrm{H}$ interactions were found to be transferable ${ }^{32,33}$ to other hydrocarbon molecules and can therefore be used in a predictive mode for a limited set of molecules. This model is labeled NIPE, an acronym for neo- pentane, isopropane, propane, and ethane, the potential energy landscapes from which the parameters were regressed.

In this work, we determine energy landscapes of methanol and ethanol dimer pairs. These dimers contain a strong directional attraction due to hydrogen bonding. In this case, substantial charge separation in the monomer itself is expected to dominate some characteristics of the resultant energy surface, but electron correlation effects are still expected to play an important role. We also examine the possibility of representing the resultant potential energy surfaces with an extension to the NIPE model.

\section{COMPUTATIONAL DETAILS}

Calculations were made with MP2/6-311+G(2df, 2pd) using GAUSSIAN $98 .{ }^{60}$ This maintains consistency with our previously obtained potential energy landscapes for molecules with interactions dominated by electron correlation. $^{32-36}$ We previously found good agreement between methane dimer energies calculated using MP2/6-311 $+\mathrm{G}(2 d f, 2 p d)$ and the much more expensive MP4/aug-cc-pVTZ. ${ }^{2}$ Others have shown good agreement between CCSD(T) and MP2 with a large basis set ${ }^{12}$ and between higher perturbation orders and MP2. ${ }^{24,37,38}$ Geometries of the isolated monomers optimized with MP2/6-311 $+\mathrm{G}(2 d f, 2 p d)$ and model point charges obtained from the electrostatic potential (ESP) method are shown in Fig. 1. These geometries were used without relaxation to determine $a b$ initio data for unique dimer orientations. Use of rigid monomers is standard procedure and appropriate for development of simple, nonpolarizable models often used in simulations, though dimer optimization can be used to help develop polarizable models.

All potential energies of the dimer pair were CP corrected to minimize BSSE. Potential energy scans were performed for the dimers along routes of fixed relative monomer orientations. The routes were defined in terms of an approach axis along which the distance between the two monomers was varied. Figure 2 defines the geometrical terms that are used throughout this paper to define the approach routes. In all cases, the origin for the coordinate system for each monomer is the primary alcohol $\mathrm{C}$ atom (labeled $\mathrm{C}_{\alpha}$ ). Standard monomer orientation, depicted in the left-hand drawing of Fig. 2, places the $\mathrm{C}_{\alpha}-\mathrm{O}$ bond along the $z$ axis with the $\mathrm{O}-\mathrm{H}$ bond parallel to the $x$ axis. Dimer route orientations are defined in terms of the yaw, pitch, and roll angles of the second monomer relative to the standard orientation shown in Fig. 2; the first monomer is fixed in standard orientation. As shown in Fig. 2 , yaw $\left(0^{\circ} \leqslant\right.$ yaw $\left.<360^{\circ}\right)$ represents a right-hand rotation about the $z$ axis, pitch $\left(-90^{\circ} \leqslant\right.$ pitch $\left.\leqslant 90^{\circ}\right)$ represents a right-hand rotation about the $y$ axis, and roll $\left(-180^{\circ}\right.$ $\leqslant$ roll $\leqslant 180^{\circ}$ ) represents a right-hand rotation about the $x$ axis. The relative spatial location of each monomer origin is characterized by the spherical coordinate triplet $(r, \theta, \phi)$ for the vector from the first monomer origin to the second. This 


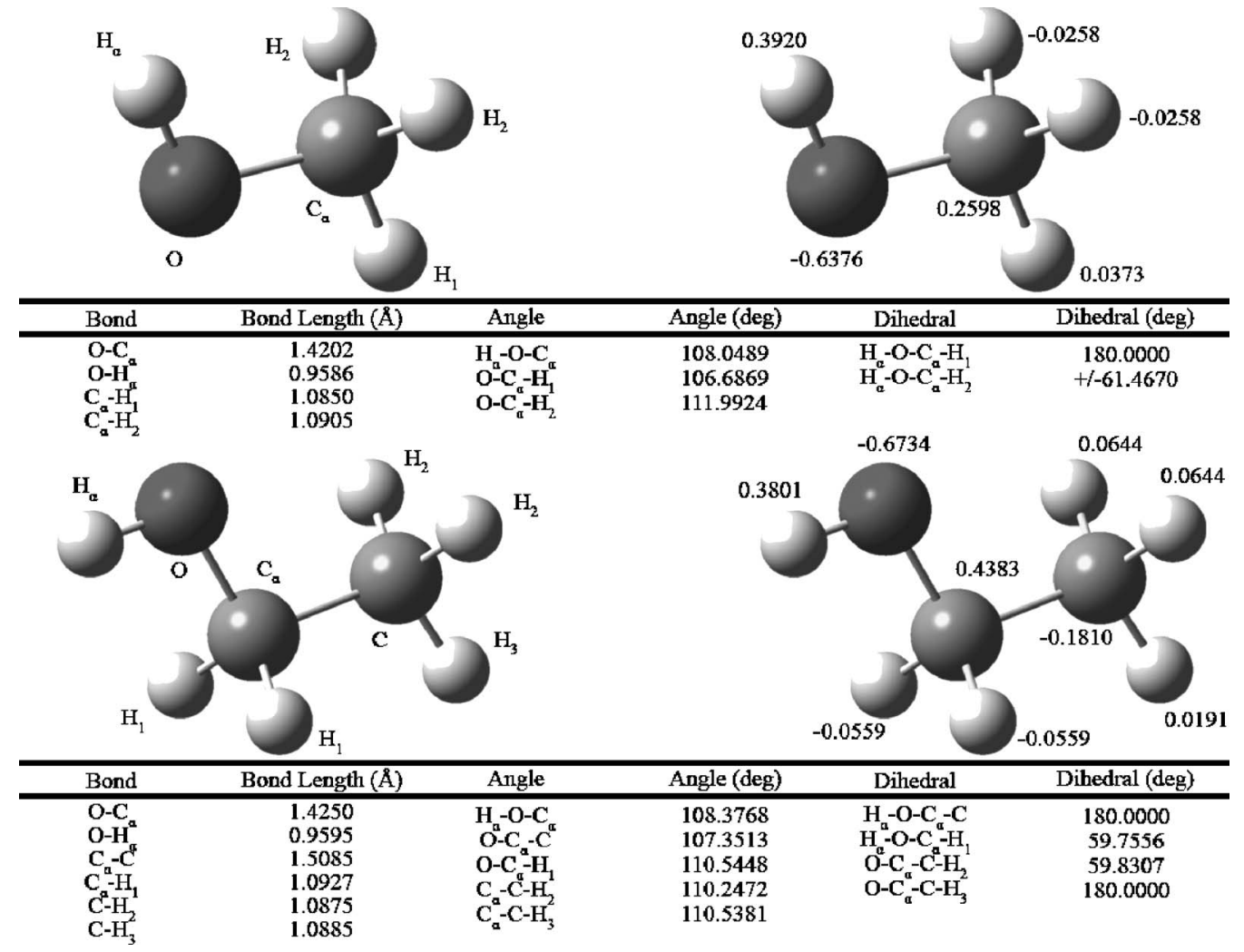

FIG. 1. Optimized geometry and charge distribution (ESP) for methanol and ethanol.

is depicted in the right-hand diagram of Fig. 2 where it can be seen that $\theta\left(-180^{\circ} \leqslant \theta<180^{\circ}\right)$ specifies the angle between the origin-to-origin vector and the $x$ axis, $\phi\left(-90^{\circ}\right.$ $\leqslant \phi \leqslant 90^{\circ}$ ) specifies the azimuthal angle between the vector and the $x-y$ plane, and $r$ specifies the distance between the origins.

The primary variable for the energy scans was $r$, the distance between the positions of the two $\mathrm{C}_{\alpha}$ nuclei. The approach axis for most routes coincided with the origin-toorigin (or $\mathrm{C}_{\alpha}$ to $\mathrm{C}_{\alpha}$ ) vector, leaving $\theta$ and $\phi$ unchanged as the distance along the approach axis was varied. A few approach axes were selected that do not lie along the origin-toorigin vector. In these cases, it is convenient to parametrize $\theta$ and $\phi$ in terms of $r$ so that the results from all routes can be represented as a function of the single independent separation variable $r$. Tables I and II show the routes characterized in terms of these five coordinates (yaw, pitch, and roll of the second monomer; $\theta$ and $\phi$ of the origin-to-origin vector) for each dimer pair. For those cases in which $\theta$ and $\phi$ are a function of $r$, the coefficients ( $a, b$, and $c$, respectively) in
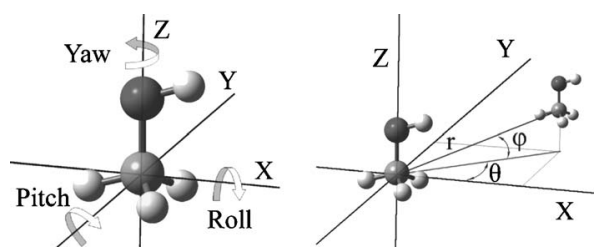

FIG. 2. Illustration of yaw, pitch, roll, $r, \theta$, and $\varphi$ coordinates to describe dimer approach routes.

$$
\theta, \phi=\sin ^{-1}\left(\frac{a}{r^{2}}+\frac{b}{r}+c\right)
$$

are listed in the table rather than actual angles. Yaw was allowed to change in two of the methanol routes and the coefficients ( $a$ and $b$, respectively) in

$$
\text { yaw }=a+b r
$$

appear in Table I rather than a fixed yaw value. Typically dimer energies along each route were calculated at 15 different separation distances, $r$. A total of $607 \mathrm{CP}$ corrected energies was obtained. A thumbnail picture of the route in the left column shows the approach axis (line) between the monomers. (In many cases, the correspondence between the visually significant thumbnail approach picture and the quantitative values for yaw, pitch, roll, $\theta$, and $\phi$ may not be apparent because the first monomer is not shown in standard orientation in the approach axis picture.) The central site, represented with a smaller sphere, is a dummy site used in the scans to vary $r$ while maintaining fixed monomer geometries.

\section{RESULTS AND DISCUSSION}

Results of the dimer potential energies for each of the routes are shown in Figs. 3 and 4. Route numbers defined in Tables I and II are shown in the legends, but the routes are loosely grouped in the figures by primary interaction type. 
TABLE I. Methanol routes in terms of the approach axis (line with central smaller sphere connecting the two $\mathrm{C}$ atoms), and defined by yaw, pitch, roll, $\theta$, and $\phi$ coordinates. Multiple values represent the coefficients in Eq. (1) for $\theta$ and $\phi$ or Eq. (2) for yaw.

\begin{tabular}{|c|c|c|c|c|c|c|}
\hline Approach & Number & Yaw & Pitch & Roll & $\theta$ & $\varphi$ \\
\hline & 1 & 180.00 & -71.93 & 0.00 & -180.00 & 35.98 \\
\hline & 2 & 0.00 & 0.00 & 0.00 & -180.00 & 35.98 \\
\hline & 3 & 180.00 & -71.96 & 0.00 & 0.00 & -35.98 \\
\hline & 4 & 180.00 & 0.00 & 180.00 & 0.00 & $\begin{array}{c}2.4012 \\
1.6275 \\
-0.5715 \\
\end{array}$ \\
\hline & 5 & 180.00 & 0.00 & 180.00 & 0.000 & 90.00 \\
\hline & 6 & $\begin{array}{l}139.4 \\
0.921 \\
\end{array}$ & -28.39 & 113.11 & $\begin{array}{c}0.3667 \\
-0.7224 \\
-0.0013 \\
\end{array}$ & $\begin{array}{r}0.8757 \\
0.9101 \\
-0.5864 \\
\end{array}$ \\
\hline & 7 & 180.00 & 0.00 & 180.00 & 0.00 & -90.00 \\
\hline & 8 & 0.00 & 0.00 & -180.00 & 0.00 & -90.00 \\
\hline & 9 & 0.00 & -71.95 & 0.00 & 0.00 & $\begin{array}{c}-0.3099 \\
1.29 \\
0.3095 \\
\end{array}$ \\
\hline & 10 & 180.00 & 71.93 & 180.00 & -180.00 & -18.05 \\
\hline & 11 & 0.00 & -54.02 & 0.00 & -180.00 & $\begin{array}{l}-0.0119 \\
-0.1627 \\
0.5874 \\
\end{array}$ \\
\hline & 12 & 0.00 & 17.96 & 180.00 & -180.00 & $\begin{array}{l}-2.4146 \\
2.1464 \\
0.5805 \\
\end{array}$ \\
\hline & 13 & $\begin{array}{c}32.408 \\
1.126 \\
\end{array}$ & -16.127 & -98.667 & $\begin{array}{c}-0.1378 \\
0.5507 \\
0.0051 \\
\end{array}$ & $\begin{array}{c}-1.0206 \\
0.9095 \\
0.5855 \\
\end{array}$ \\
\hline . & 14 & 90.01 & 0.00 & 161.98 & -90.00 & $\begin{array}{r}3 \times 10^{-5} \\
2.7706 \\
-6 \times 10^{-7} \\
\end{array}$ \\
\hline $5-a$ & 15 & 180.00 & -71.93 & 180.00 & -180.00 & $\begin{array}{r}-0.9778 \\
0.0134 \\
0.9993 \\
\end{array}$ \\
\hline ap & 16 & 180.00 & 0.000 & 180.00 & 0.00 & $\begin{array}{l}-0.4274 \\
0.0023 \\
0.9999\end{array}$ \\
\hline 5 & 17 & 0.00 & 0.00 & 0.00 & -180.00 & $\begin{array}{l}-0.1847 \\
-0.6256 \\
0.5873 \\
\end{array}$ \\
\hline b & 18 & 180.00 & 54.03 & 0.00 & -180.00 & $\begin{array}{r}-0.4186 \\
0.9375 \\
0.587 \\
\end{array}$ \\
\hline के & 19 & 180.00 & 36.10 & 0.00 & 0.00 & 18.05 \\
\hline
\end{tabular}

The grouping is reflective of the common site-site model in which the potential energy is viewed as the sum of site-site pair potentials with each atomic center viewed as an interacting site. Routes grouped together tend to bring similar sites toward each other along the approach axis. For example, those routes in which an $\mathrm{O}$ atom on one monomer approaches a $\mathrm{H}$ atom as $r$ is decreased are grouped together as type $\mathrm{O}-\mathrm{H}$.

\section{A. Methanol dimer potential energies}

Calculated methanol dimer potential energies are shown in Fig. 3 for the 19 routes identified in Table I. The first six routes shown in Fig. 3 are O-O-type routes. Route 1 is entirely repulsive due to the large electron density around the $\mathrm{O}$ atoms. Routes 2 and 5 exhibit substantial attractive wells of approximately $-1.7 \mathrm{kcal} / \mathrm{mol}$ in spite of the $\mathrm{O}-\mathrm{O}$ orienta- tion. These approach routes position the alcohol $\mathrm{H}$ in a relatively favorable position for hydrogen bonding with the $\mathrm{O}$ atom of the opposing monomer, lowering the potential energy. Routes 3 and 6 are only slightly repulsive with minima in the repulsions near $r=4 \AA$. Because the $\mathrm{O}$ atoms are on the "backside" of the approach axis for routes 3,4 , and 6 , the $\mathrm{O}-\mathrm{O}$ repulsion is attenuated by the distance between the $\mathrm{O}$ sites allowing the $\mathrm{O}-\mathrm{H}$ and $\mathrm{O}-\mathrm{C}$ attractions to even create a modest $(-0.5 \mathrm{kcal} / \mathrm{mol})$ attractive well for route 4 and produce the minima in routes 3 and 6 .

Routes 7 and 8 of $\mathrm{C}-\mathrm{C}$ type and route 10 of $\mathrm{C}-\mathrm{H}$ type exhibit relatively shallow wells (between -0.2 and $-0.3 \mathrm{kcal} / \mathrm{mol}$ ) typical of dispersion interactions between $\mathrm{C}$ and $\mathrm{H}$ atoms as previously observed for alkanes. ${ }^{33-35}$ The $\mathrm{O}$ and $\mathrm{H}$ atoms are at opposite ends of the dimer and play only a minor role in the interactions. Route 9 is different than the 
TABLE II. Ethanol routes in terms of the approach axis (line with central smaller sphere connecting the two C atoms), and defined by yaw, pitch, roll, $\theta$, and $\phi$ coordinates. Multiple values represent the coefficients in Eq. (1) for $\theta$ and $\phi$ or Eq. (2) for yaw.

\begin{tabular}{|c|c|c|c|c|c|c|}
\hline Approach & Number & Yaw & Pitch & Roll & $\theta$ & $\varphi$ \\
\hline 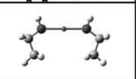 & 1 & 0.00 & -73.49 & 180.00 & -180.00 & $\begin{array}{l}-1.5156 \\
1.1837 \\
0.7967\end{array}$ \\
\hline & 2 & 180.00 & 0.00 & 180.00 & -180.00 & $\begin{array}{c}-0.071 \\
-0.0296 \\
0.801\end{array}$ \\
\hline & 3 & 180.00 & -71.62 & -0.04 & 0.00 & $\begin{array}{r}-0.8611 \\
1.8109 \\
-0.5978 \\
\end{array}$ \\
\hline & 4 & 180.00 & 0.00 & 180.00 & 0.00 & $\begin{array}{l}-0.0025 \\
-0.0291 \\
-0.8015 \\
-0.80\end{array}$ \\
\hline & 5 & 0.00 & 0.00 & 0.00 & -180.00 & $\begin{array}{r}-1.2419 \\
0.9066 \\
0.8086 \\
\end{array}$ \\
\hline & 6 & 180.00 & 36.76 & 0.00 & -180.00 & $\begin{array}{c}0.0263 \\
-0.0306 \\
0.801 \\
\end{array}$ \\
\hline & 7 & 180.00 & 0.00 & -180.00 & 0.00 & $\begin{array}{r}0.1915 \\
-0.6075 \\
-0.5862 \\
\end{array}$ \\
\hline & 8 & 0.00 & 71.63 & 180.00 & -180.00 & $\begin{array}{r}-0.0002 \\
-0.7462 \\
-0.6323 \\
0.8008 \\
\end{array}$ \\
\hline & 9 & 180.00 & 0.00 & 180.00 & -180.00 & $\begin{array}{l}-1.2306 \\
-0.4871 \\
0.7989 \\
\end{array}$ \\
\hline & 10 & 180.00 & 0.00 & 180.00 & -180.00 & $\begin{array}{l}-1.3661 \\
-2.671 \\
0.8373 \\
\end{array}$ \\
\hline بs & 11 & 0.00 & 18.48 & 180.00 & 0.00 & $\begin{array}{l}1.1532 \\
-0.9933 \\
-0.5905\end{array}$ \\
\hline & 12 & 180.00 & 0.00 & 180.00 & -180.00 & $\begin{array}{r}-0.1 .4246 \\
-1.2416 \\
-0.3008\end{array}$ \\
\hline 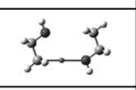 & 13 & 180.00 & 0.00 & 180.00 & -180.00 & $\begin{array}{r}-1.9507 \\
-1.6644 \\
0.8139 \\
\end{array}$ \\
\hline 5 & 14 & 180.00 & -18.45 & 0.00 & -180.00 & $\begin{array}{l}-2.01077 \\
1.7955 \\
0.5955 \\
\end{array}$ \\
\hline+5 & 15 & 0.00 & 34.91 & 180.00 & 0.00 & $\begin{array}{l}0.4663 \\
0.2158 \\
0.3255 \\
\end{array}$ \\
\hline $3^{2}$ & 16 & 180.00 & 0.00 & 180.00 & -180.00 & $\begin{array}{l}0.7954 \\
0.4257 \\
0.8045 \\
\end{array}$ \\
\hline 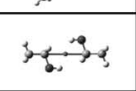 & 17 & 180.00 & 0.00 & 180.00 & 0.00 & $\begin{array}{r}0.8045 \\
-2.3068 \\
-1.3416 \\
0.3212\end{array}$ \\
\hline 2 & 18 & 180.00 & 0.00 & -180.00 & 0.00 & $\begin{array}{r}0.0212 \\
.1 .5928 \\
-1.5437 \\
-0.5876 \\
\end{array}$ \\
\hline If & 19 & 180.00 & 0.00 & 180.00 & 0.00 & 18.377 \\
\hline$+x$ & 20 & 180.00 & 36.75 & 0.00 & 0.00 & $\begin{array}{l}1.2828 \\
1.3308 \\
0.3132\end{array}$ \\
\hline$x_{2} \rightarrow x_{2}$ & 21 & 0.00 & 1.06 & 0.00 & 0.00 & $\begin{array}{r}0.3134 \\
2.8989 \\
2.2807 \\
0.3306 \\
\end{array}$ \\
\hline मx, & 22 & 0.00 & -71.62 & 0.00 & 0.00 & $\begin{array}{r}-0.5500 \\
0.2772 \\
0.3586 \\
0.3179\end{array}$ \\
\hline
\end{tabular}

other $\mathrm{C}-\mathrm{H}$ type (route 10 ) in that it is the $\mathrm{H}_{\alpha}$ that approaches the $\mathrm{C}$. The charge distribution shown in Fig. 1 shows that both the $\mathrm{H}_{\alpha}$ and $\mathrm{C}$ in question have a positive charge, and the strong electron-withdrawing effect of the $\mathrm{O}$ atom makes this approach more repulsive than route 10 .

Routes 11-17 all emphasize $\mathrm{O}-\mathrm{H}_{\alpha}$ interactions. All show deep attractive wells characteristic of hydrogen bonding. The well depths for routes 15 and 17 are approximately half those for the other routes. The attractive wells are deepest for routes 11-13 in which a direct, unobstructed $\mathrm{O}-\mathrm{H}_{\alpha}$ approach (the $\mathrm{H}$ from the second monomer bisects the
$\mathrm{H}-\mathrm{O}-\mathrm{C}$ angle of the first monomer) produces a strong hydrogen bond. The attractive well is weakened for some of the other routes (see route 17 , for example) as other similarly charged sites on the two monomers interact and moderate the attractions created by the $\mathrm{O}-\mathrm{H}_{\alpha}$ interactions. The relative depth of the wells can be explained in terms of relative distances between positive charged atoms of the two methanol molecules in each approach. When there are smaller distances between atoms of similar charges, there is a shallower well since the repulsive charge effects give higher potential energies (as can be seen in routes 15 and 17). 

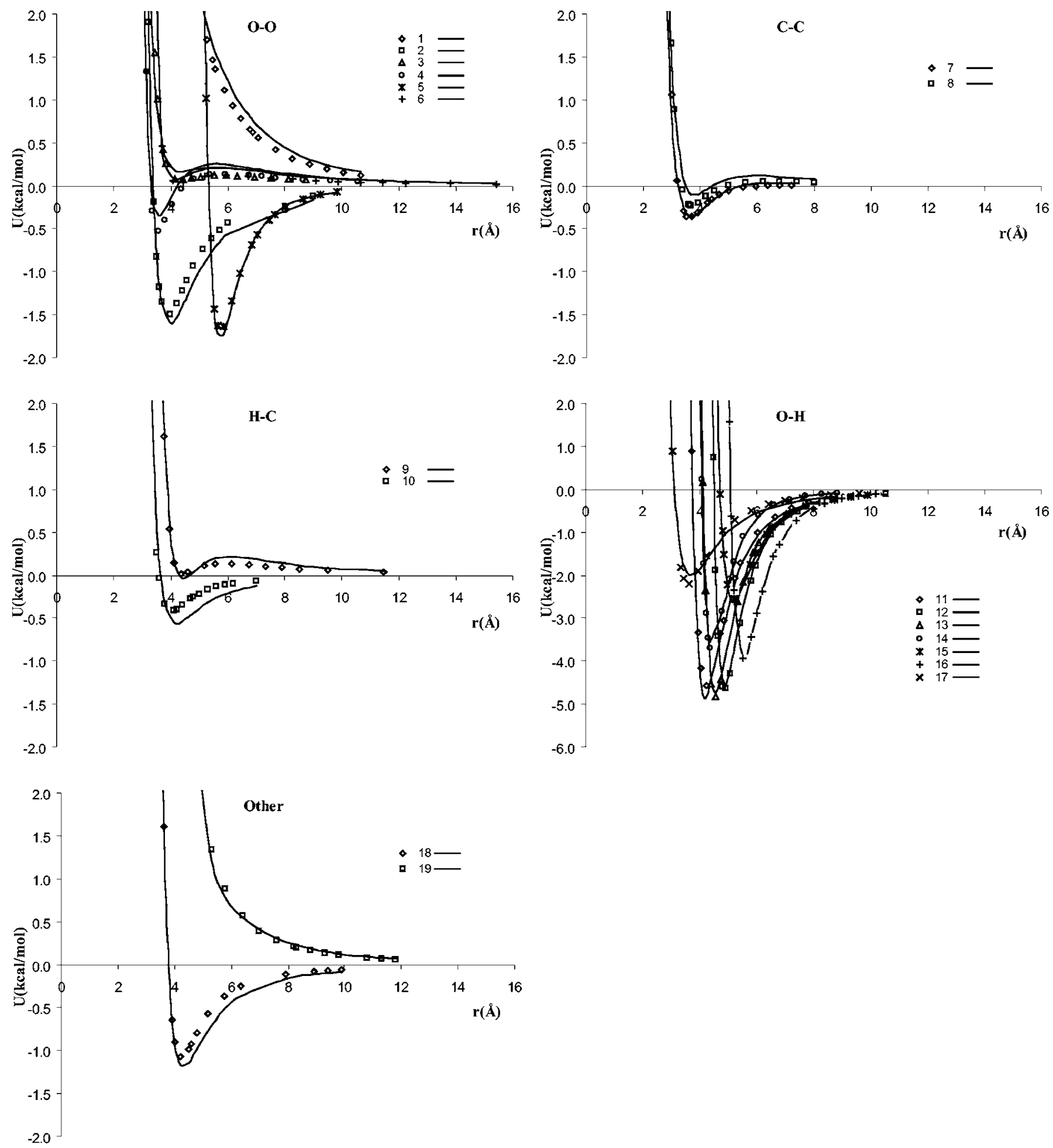

FIG. 3. Dimer energies for methanol as a function of distance between $\mathrm{C}_{\alpha}$ monomer sites from ab initio calculations (points) and from the site-site model with point charges (lines).

Route 18 (type other) has a significant attractive well because all three $\mathrm{H}$ atoms on the methyl group approach the $\mathrm{O}$. The approach in route 19 brings directly together the two $\mathrm{H}_{\alpha}$ atoms, and the resultant potential well is dominated by the $\mathrm{H}_{\alpha}-\mathrm{H}_{\alpha}$ repulsions.

\section{B. Ethanol dimer potential energies}

Figure 4 shows the ethanol dimer potential energies for the 22 routes identified in Table II. Routes 1-5 are O-O-type routes and the results are similar to those obtained for methanol: routes 1 and 2 are purely repulsive, routes 3 and 4 have small attractive wells $(\sim-0.2 \mathrm{kcal} / \mathrm{mol})$ because the $\mathrm{O}-\mathrm{H}$ and $\mathrm{O}-\mathrm{C}$ attractions favorably compete with the $\mathrm{O}-\mathrm{O}$ repulsion, attenuated somewhat by the backside orientation of the oxygen atoms for these routes. Route 5 exhibits an attractive well of $-1.2 \mathrm{kcal} / \mathrm{mol}$ for the "frontside-backside" orientation of the $\mathrm{O}$ atoms that permits larger $\mathrm{O}-\mathrm{H}$ attractive contributions. 

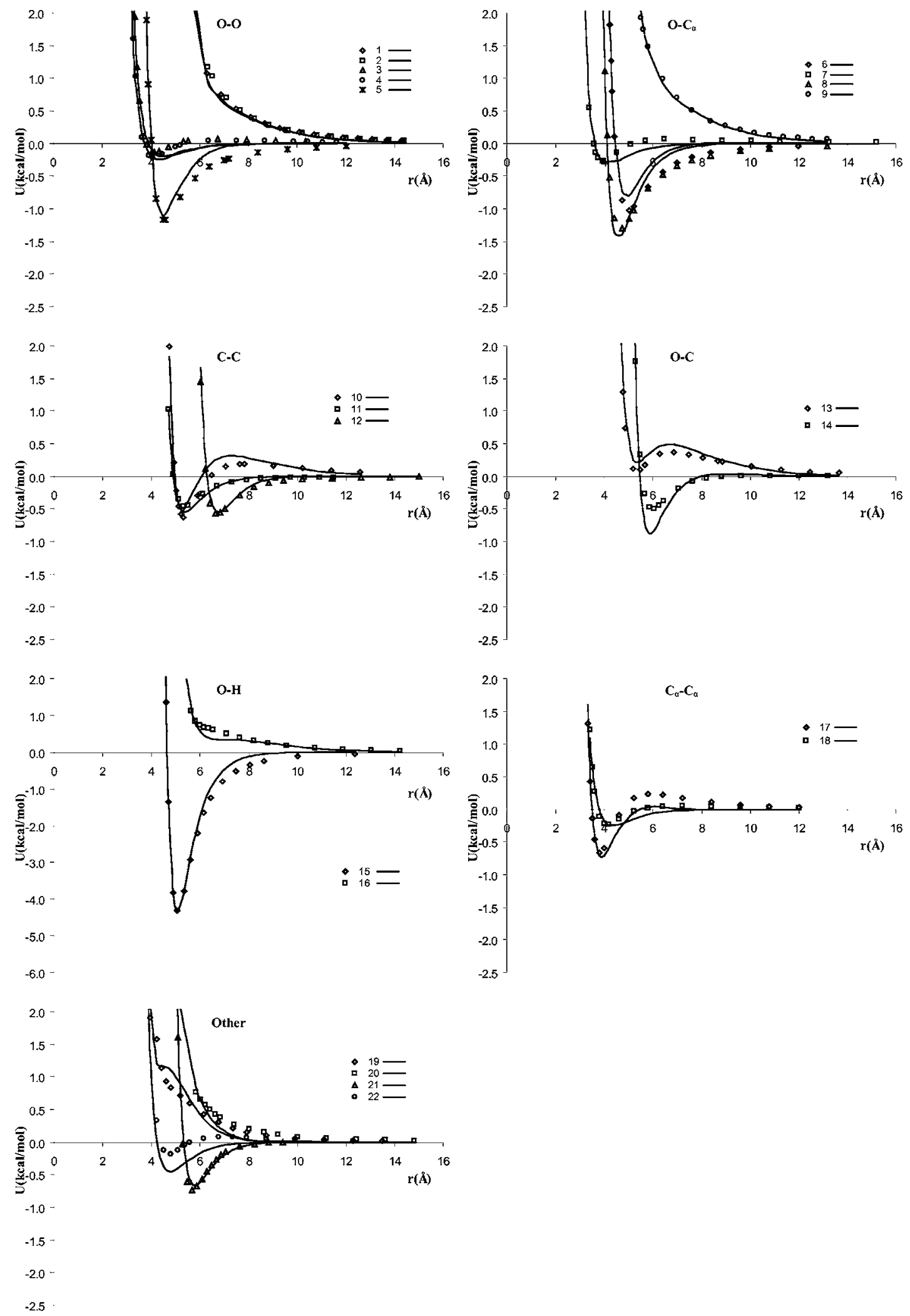

FIG. 4. Dimer energies for ethanol as a function of distance between $\mathrm{C}_{\alpha}$ monomer sites from ab initio calculations (points) and from the site-site model without point charges (lines).

The four $\mathrm{O}-\mathrm{C}_{\alpha}$ approaches demonstrate surfaces explicable with the monomer ESP charge distribution, dominated by the negative charge localized at the $\mathrm{O}$ center and the positive charge on the $\mathrm{C}_{\alpha}$ atom. The orientations for routes 6 and 8 allow closer approach of the $\mathrm{O}$ and $\mathrm{C}_{\alpha}$ sites producing moderately deep wells, but route 7 has only a shallow attractive well $(-0.27 \mathrm{kcal} / \mathrm{mol})$ because of the simultaneous proximity of $\mathrm{C}_{\alpha}$ and $\mathrm{H}_{\alpha}$, both of which have a net positive charge. There is a very subtle valley in the repulsive region of this route in the region $7 \AA<r<10 \AA$ that presumably 
arises from the competitive effects of the various changing distances between the sites along this route. Though the $\mathrm{O}$ and $\mathrm{C}_{\alpha}$ atoms approach each other in route 9 , the angle of approach also brings the two $\mathrm{O}$ atoms together and the latter repulsions dominate.

As in the methanol case routes 10-12, grouped together as $\mathrm{C}-\mathrm{C}$ approaches, show typical alkane-type dispersion interactions with modest attractive wells since $\mathrm{O}$ and $\mathrm{H}_{\alpha}$ atoms are at opposite ends of the dimer. However, route 10 also shows a shoulder near $r=8 \AA$ likely arising from the repulsive close proximity of the $\mathrm{O}$ and $\mathrm{C}$ atoms. A competition between this inherently repulsive $\mathrm{O}-\mathrm{C}$ interaction and the dispersion attraction of electron correlation is likely the cause of the shoulders observed in routes 13 and 14, labeled as type O-C. Route 13 aligns two $\mathrm{O}-\mathrm{C}$ interactions and is more repulsive than route 14 that focuses on a single, direct $\mathrm{O}-\mathrm{C}$ interaction.

Route 15 probes a direct $\mathrm{O}-\mathrm{H}$ interaction and exhibits a deep attractive well $(-4.3 \mathrm{kcal} / \mathrm{mol})$ characteristic of hydrogen bonding. Initially surprising to us was the purely repulsive route 16 which we thought would also exhibit a deep attractive well because of the $\mathrm{O}-\mathrm{H}$ approach, but the results show an entirely repulsive potential most likely due to the relative proximity of the two $\mathrm{O}$ atoms.

Routes 17 and 18 both show repulsive shoulders around $r=7 \AA$ with shallow attractive wells around $r=4 \AA$. This behavior is likely due to the expected repulsive nature of the $\mathrm{C}_{\alpha}-\mathrm{C}_{\alpha}$ interactions expected at longer distances for these orientations that is overcome by the larger magnitude of the $\mathrm{O}-\mathrm{C}_{\alpha}$ interactions that become significant at shorter $r$ values as these two sites are brought into closer proximity.

The routes classified as type "other" show a range of behaviors. Routes 19 and 20 are purely repulsive as would be expected from the monomer charge distributions. Route 20 focuses directly on the $\mathrm{H}_{\alpha}-\mathrm{H}_{\alpha}$ approach and is correspondingly more repulsive than route 19 , which brings the $\mathrm{H}_{\alpha}$ and $\mathrm{C}_{\alpha}$ sites toward each other. The $-0.73 \mathrm{kcal} / \mathrm{mol}$ narrow, attractive well in route 21 is due to the attractive nature of the $\mathrm{H}_{\alpha}-\mathrm{C}$ interaction. Route 22 exhibits a very shallow attractive well at closer distances and a repulsive shoulder at middistances. For this orientation, there is evidently competition between the dispersion interactions at closer range, when the $\mathrm{C}$ site is close enough to produce significant attractions, and the repulsive $\mathrm{H}_{\alpha}-\mathrm{C}_{\alpha}$ interactions that will dominate at larger separation distances.

\section{PAIRWISE-ADDITIVE ATOMIC POTENTIALS}

The complex, multidimensional potential energy surfaces for these dimers, though of interest in and of themselves, are more easily used in molecular simulations and other modeling work when represented quantitatively with explicit mathematical equations. Adequate correlation of the entire surface in terms of the six variables, yaw, pitch, roll, $r$, $\theta$, and $\phi$, seems a daunting task since the physics do not suggest a particular model for the correlation. However, the concept of site-site interactions worked well in understanding and explaining the ab initio results, and this suggests that a sum of spherically symmetric, site-site, pair interactions may be a convenient and simple method to represent the very complex pair potential surfaces. Previously, the NIPE model $^{33}$ has been used to effectively represent supermolecule results for hydrocarbons, and we attempt to extend those results here to alcohols. The NIPE model has also been extended to unsaturated hydrocarbons with $\pi$ electrons by adding satellite sites to represent higher electron density regions, ${ }^{61}$ and we adopt that approach here.

We choose to represent the total dimer potential, $U$, as a sum of site-site pair interactions:

$$
U(\text { yaw, pitch, roll, } r, \theta, \varphi)=\sum_{i=1}^{N S} \sum_{j=1}^{N S} u_{i j}\left(r_{i j}\right)
$$

where the double sum runs over the number of sites, NS (equal to the number of atoms in this all-atom model) in each monomer and $u_{i j}$ is the pair potential between site $i$ on monomer 1 and site $j$ on monomer 2. Considerable simplification arises in this model through the assumption that the relative orientations of the monomers can be accounted for using spherically symmetric site-site models at nuclear positions. In this model, the fixed monomer bond lengths and angles replace the relative orientation information contained in the yaw, pitch, roll, $\theta$, and $\phi$ specification.

To maintain consistency with the NIPE model for hydrocarbons, we use the modified Morse equation for the site-site potential with the additional possibility of Coulombic interactions for monomers with polar groups:

$$
u_{i j}=-\varepsilon_{i j}\left(1-\left\{1-\exp \left[-A_{i j}\left(r_{i j}-r_{i j}^{*}\right)\right]\right\}^{2}\right)+\frac{z_{i} z_{j} e^{2}}{4 \pi \varepsilon_{0} r_{i j}},
$$

where $z_{i}$ is the fractional electron charge on site $i, e$ is the electron charge, and $\varepsilon_{0}$ is the free space permittivity. The values for $z_{i}$ are obtained from the ESP charge distributions shown in Fig. 1. The three adjustable parameters $\varepsilon, A$, and $r^{*}$ represent the dispersion well depth, well shape factor, and the location of the minimum in the potential well, respectively. In previous studies we have found the modified Morse model to be superior to Lennard-Jones and exp-6-type models in fitting potential energy landscapes. ${ }^{2,34,35}$ Garrison and Sandler ${ }^{54}$ have shown that Gibbs ensemble simulations using a site-site Morse-C6 model for acetylene accurately reproduce the experimental vapor-liquid phase dome. Hayes et $a l .{ }^{56}$ found that $a b$ initio methane potential energy surfaces modeled with a Morse potential produced simulated thermodynamic properties in better agreement than the more commonly used parameter sets and models.

In addition to nuclear sites, we use a satellite site, $X$, to represent the off-center high electron density of the electron pairs on the $\mathrm{O}$ atom. The satellite site was placed on the vector bisecting the $\mathrm{C}_{\alpha}-\mathrm{O}-\mathrm{H}_{\alpha}$ angle of the alcohol, but on the side of the $\mathrm{O}$ opposite the $\mathrm{C}_{\alpha}-\mathrm{O}$ and $\mathrm{O}-\mathrm{H}_{\alpha}$ bonds. To keep the number of adjustable parameters manageable, we assumed that all interactions with the satellite site were zero except for $\mathrm{H}_{\alpha}-X$ and $X-X$. The $\mathrm{H}_{\alpha}-X$ interaction was modeled with Eq. (4), but the $X-X$ interaction was simplified to a purely repulsive interaction modeled with 


$$
u_{X X}=B_{X X} \exp \left(-C_{X X} r_{X X}\right) .
$$

Values of the parameters $B_{X X}$ and $\mathrm{C}_{X X}$ and the $\mathrm{O}-X$ distance were regressed from the $a b$ initio potential landscapes simultaneously with the site-site parameters of Eq. (4).

The potential energy surface for each molecule was regressed twice: once with the charges shown in Eq. (4) turned on and once with all the charges turned off. In both cases 33 parameters were adjusted for the methanol dimer and 42 were adjusted for the ethanol dimer. The ESP charges on the $\mathrm{C}_{\alpha}$ and $\mathrm{H}_{\alpha}$ atoms are significantly different than those from which the NIPE parameters were regressed and parameters in Eq. (4) were regressed for all pair interactions involving these sites. However, the nonhydroxyl $\mathrm{H}-\mathrm{H}$ interactions and for ethanol the $\mathrm{C}-\mathrm{C}$ and $\mathrm{C}-\mathrm{H}$ interactions were fixed at their NIPE values and not adjusted in the regression. To maintain consistency with the NIPE model, the small charges on sites treated with the NIPE parameters were set to zero and the remaining charges in the monomer were normalized to the values shown in Table III. Adjustable methanol parameters therefore included three Morse potential parameters for the nine unique new nuclear site-site interactions and the $\mathrm{H}_{\alpha}-X$ interaction, two parameters for the $X-X$ interactions modeled with Eq. (5), and the $\mathrm{O}-X$ distance. Similarly, the adjustable parameters for ethanol included three Morse parameters each for the 12 unique new nuclear site-site interactions and the $\mathrm{H}_{\alpha}-X$ interaction, two parameters for the $X-X$ repulsion, and the $\mathrm{O}-X$ distance. Model parameters were regressed separately for each dimer pair from the corresponding energy landscape using a simulated annealing algorithm. The parameters obtained from the regression are shown in Table III.

Also shown in Table III is the sum of squared errors (SSEs) per point obtained from the regression. The pairwiseadditive, site-site models used represent the complexities of the $a b$ initio potential energy surfaces quite well. The potential energies calculated using the model for methanol with charges are shown (as lines) in Fig. 3; ethanol potential energies modeled without charges are shown (as lines) in Fig. 4. Both models are seen to compare well to the ab initio values. The $\mathrm{O}-\mathrm{O}$ routes are adequately reproduced by the model including the small shoulders in routes 3, 4, and 6 at approximately $5.5 \AA$, though the shoulder is slightly overemphasized by the model. The model makes route 1 slightly more repulsive than the $a b$ initio data. All 11 of the routes classified as $\mathrm{C}-\mathrm{C}, \mathrm{O}-\mathrm{H}$, and other are reliably reproduced. The model accurately reflects the well depths and positions for these routes, including the repulsive-attractive behavior of routes 7 and 8 and the entirely repulsive behavior of route 19. The model slightly overpredicts the attraction of $\mathrm{H}-\mathrm{C}$ route 10 and suggests a slightly larger repulsive shoulder for $\mathrm{H}-\mathrm{C}$ route 9 , though the agreement of the repulsive-neutralrepulsive shape is still quite good. Similar good agreement between the model and the $a b$ initio data is observed in Fig. 4 for ethanol using the model without charges. The O-O routes are quantitatively reproduced by the model significantly better than when charges are included (not shown). The model reproduces all four $\mathrm{O}-\mathrm{C}_{\alpha}$ routes, though the model well breadth is a little too narrow for the attractive
TABLE III. Methanol and ethanol model parameters for Eqs. (4) and (5) regressed with and without point charges. Parameter values are given in the order $\varepsilon(\mathrm{kcal} / \mathrm{mol}), A\left(\AA^{-1}\right)$, and $r^{*}(\AA)$, respectively, for Eq. (4) and in the order $B(\mathrm{kcal} / \mathrm{mol}), C\left(\AA^{-1}\right)$, and $r_{\text {ox }}(\AA)$ for the $X-X$ interaction.

\begin{tabular}{|c|c|c|c|c|}
\hline \multirow[b]{2}{*}{ Interaction } & \multicolumn{2}{|c|}{ With point charges } & \multicolumn{2}{|c|}{ Without point charges } \\
\hline & Methanol & Ethanol & Methanol & Ethanol \\
\hline \multicolumn{5}{|c|}{ SSE (sum of squared errors per point) } \\
\hline SSE & 0.012 & 0.047 & 0.030 & 0.017 \\
\hline \multicolumn{5}{|c|}{ Regressed parameters } \\
\hline \multirow[t]{3}{*}{$\mathrm{O}-\mathrm{O}$} & 0.28128 & 8.49412 & 0.56237 & 0.03292 \\
\hline & 2.01169 & 0.92972 & 1.18149 & 0.89878 \\
\hline & 3.14862 & 0.67646 & 3.74311 & 5.8420 \\
\hline \multirow[t]{3}{*}{$\mathrm{O}-\mathrm{C}_{\alpha}$} & 0.00049 & $1.79 \times 10^{-5}$ & 0.14519 & 2.31319 \\
\hline & 2.87970 & 0.77318 & 0.93092 & 1.84553 \\
\hline & 3.98955 & 2.60416 & 4.16094 & 2.99986 \\
\hline \multirow[t]{3}{*}{$\mathrm{O}-\mathrm{C}$} & $\cdots$ & 7.16564 & $\cdots$ & 2.62034 \\
\hline & $\cdots$ & 1.46978 & $\cdots$ & 1.79601 \\
\hline & $\cdots$ & 2.57620 & $\cdots$ & 2.95039 \\
\hline \multirow{3}{*}{$\mathrm{O}-\mathrm{H}_{\alpha}$} & 0.00953 & 3.61543 & 12.46392 & 18.0197 \\
\hline & 2.39278 & 1.85755 & 1.62717 & 1.64599 \\
\hline & 0.96556 & 1.93924 & 1.50634 & 1.47544 \\
\hline \multirow[t]{3}{*}{$\mathrm{O}-\mathrm{H}$} & $4.79 \times 10^{-6}$ & $6.17 \times 10^{-5}$ & 0.52961 & 0.00254 \\
\hline & 1.44640 & 0.94407 & 1.28496 & 1.01726 \\
\hline & 6.75499 & 8.28351 & 2.94761 & 5.77252 \\
\hline \multirow[t]{3}{*}{$\mathrm{C}_{\alpha}-\mathrm{C}_{\alpha}$} & 0.53431 & 4.59505 & 0.27110 & 0.00077 \\
\hline & 5.42872 & 1.29692 & 3.18382 & 6.09818 \\
\hline & 0.54673 & 2.92735 & 3.21345 & 3.78185 \\
\hline \multirow[t]{3}{*}{$\mathrm{C}_{\alpha}-\mathrm{C}$} & $\cdots$ & 0.00978 & $\cdots$ & 0.18367 \\
\hline & $\cdots$ & 0.32849 & $\cdots$ & 1.66760 \\
\hline & $\cdots$ & 10.9008 & $\cdots$ & 3.82351 \\
\hline \multirow[t]{3}{*}{$\mathrm{C}_{\alpha}-\mathrm{H}_{\alpha}$} & 1.20290 & 1.74991 & 6.49019 & 6.34217 \\
\hline & 1.48559 & 2.82282 & 12.24823 & 12.6701 \\
\hline & 2.41005 & 2.38571 & 0.34630 & 0.23124 \\
\hline \multirow[t]{3}{*}{$\mathrm{C}_{\alpha}-\mathrm{H}$} & 0.30649 & 5.72187 & 0.42767 & 6.92482 \\
\hline & 1.80093 & 4.84533 & 4.77747 & 9.17206 \\
\hline & 2.67419 & 0.49777 & 0.50033 & 0.16668 \\
\hline \multirow[t]{3}{*}{$\mathrm{C}-\mathrm{H}_{\alpha}$} & $\cdots$ & 0.06512 & $\cdots$ & 0.07353 \\
\hline & $\cdots$ & 10.01582 & $\ldots$ & 5.32819 \\
\hline & $\cdots$ & 0.05860 & $\cdots$ & 0.00775 \\
\hline \multirow[t]{3}{*}{$\mathrm{H}_{\alpha}-\mathrm{H}_{\alpha}$} & 0.00303 & 0.01461 & $1.34 \times 10^{-5}$ & $6.28 \times 10^{-5}$ \\
\hline & 1.59429 & 0.94465 & 0.71522 & 0.70122 \\
\hline & 3.81180 & 5.00333 & 11.27744 & 10.48771 \\
\hline \multirow[t]{3}{*}{$\mathrm{H}_{\alpha}-\mathrm{H}$} & $9.08 \times 10^{-5}$ & 0.68571 & $6.78 \times 10^{-5}$ & $9.62 \times 10^{-7}$ \\
\hline & 0.18342 & 4.62914 & 0.38079 & 1.50906 \\
\hline & 1.38361 & 0.50073 & 14.70203 & 6.41108 \\
\hline \multirow[t]{3}{*}{$X-X$} & 0.28457 & 1.00665 & 14.63380 & 5.99551 \\
\hline & 6.79460 & 4.24048 & 0.71468 & 0.60331 \\
\hline & 0.09310 & 0.33858 & 0.96062 & 1.10795 \\
\hline \multirow[t]{3}{*}{$\mathrm{H}_{\alpha}-X$} & 0.03155 & 0.00105 & 0.86651 & 0.70186 \\
\hline & 1.81525 & 0.66751 & 0.53543 & 0.84393 \\
\hline & 2.98180 & 7.88000 & 1.63407 & 1.90702 \\
\hline
\end{tabular}


TABLE III. (Continued.)

\begin{tabular}{|c|c|c|c|c|}
\hline \multirow[b]{2}{*}{ Interaction } & \multicolumn{2}{|c|}{ With point charges } & \multicolumn{2}{|c|}{ Without point charges } \\
\hline & Methanol & Ethanol & Methanol & Ethanol \\
\hline \multicolumn{5}{|c|}{ Constants (NIPE model) } \\
\hline \multirow[t]{3}{*}{$\mathrm{C}-\mathrm{C}$} & $\cdots$ & 0.05133 & $\cdots$ & 0.05133 \\
\hline & $\cdots$ & 1.45985 & $\cdots$ & 1.45985 \\
\hline & $\cdots$ & 4.34117 & $\cdots$ & 4.34117 \\
\hline \multirow[t]{3}{*}{$\mathrm{C}-\mathrm{H}$} & $\cdots$ & 0.35562 & $\cdots$ & 0.35562 \\
\hline & $\cdots$ & 2.11174 & $\cdots$ & 2.11174 \\
\hline & $\cdots$ & 2.60211 & $\cdots$ & 2.60211 \\
\hline \multirow[t]{3}{*}{$\mathrm{H}-\mathrm{H}$} & 0.01048 & 0.01048 & 0.01048 & 0.01048 \\
\hline & 1.26072 & 1.26072 & 1.26072 & 1.26072 \\
\hline & 3.97536 & 3.97536 & 3.97536 & 3.97536 \\
\hline \multicolumn{5}{|c|}{ Normalized point charges } \\
\hline $\mathrm{O}$ & -0.6423 & -0.7217 & $\cdots$ & $\cdots$ \\
\hline $\mathrm{C}_{\alpha}$ & 0.2551 & 0.3318 & $\cdots$ & $\cdots$ \\
\hline $\mathrm{H}_{\alpha}$ & 0.3873 & 0.3899 & $\cdots$ & $\cdots$ \\
\hline $\mathrm{C}$ & $\ldots$ & 0 & $\cdots$ & $\cdots$ \\
\hline $\mathrm{H}$ & 0 & 0 & $\cdots$ & $\cdots$ \\
\hline
\end{tabular}

routes 6 and 8 . The $C-C$ routes are likewise modeled very well including the rather strong repulsive-attractive-repulsive nature of route 10 . This is also true for $\mathrm{O}-\mathrm{C}$ route 13 which has a significant shoulder, though the whole route remains repulsive. The deep attractive well of route 15 and the rather flat repulsive route 16 , of the $\mathrm{O}-\mathrm{H}$-type routes, are rather remarkably well modeled. The model for the $\mathrm{C}_{\alpha}-\mathrm{C}_{\alpha}$ and other routes is quantitatively acceptable. Both models (with and without charges) produce a small anomalous shoulder in the repulsive section of route 19 .

The SSE values indicate that the methanol landscape is fitted better using the model with point charges, but the opposite is true for ethanol. As a point of comparison, the fit of the methanol landscape to the model without charges is shown in Fig. 5. A comparison of Figs. 3 and 5 shows that the two models, while of comparable overall accuracy, do have some qualitative differences. Most of the attractive routes are fitted about comparably, but the model without charges models better the $\mathrm{H}-\mathrm{C}$ routes that were most problematic for the model with charges. Conversely, without charges the model predicts an attractive well for the entirely repulsive route 19 . Without charges the well breadth observed for route 18 is modeled quite accurately. Though not shown in a separate figure, the inclusion of charges in the ethanol model worsens the fits of the $\mathrm{O}-\mathrm{O}$ routes and route 21. It also produces an anomalous attractive region for route 19.

While it is common to model separately Coulombic and dispersion contributions to the total potential energy, it should be remembered that collocation of the actual charge distribution into point charges located at nuclear centers is itself a rather rough model for the actual interactions between the diffuse monomer charge distributions. Methods based on different algorithms for collapsing the distribution into point charges (e.g., Mulliken, ESP, etc.) often produce significantly different partial charges, making it difficult to obtain a unique, reliable representation. Use of a pointcharge model in molecular simulations often requires techniques such as the Ewald summation to handle the longrange nature of the Coulombic interaction because the number of pair interactions grows faster with increasing distance than the shrinking individual pair potentials. For noncharged molecular species this is an artifact of the pointcharge model, and the actual molecule-molecule potential decays rapidly with distance like other dispersive interactions. This is illustrated in Fig. 6 for a model dimer in which each monomer is represented as two hard spheres with centers separated by a bond distance of $d$ and a fractional electron charge of \pm 0.3 . For simplicity dimensionless separation distance and dimensionless potential defined by

$$
r^{+}=\frac{r}{d}, \quad u^{+}=\frac{4 \pi \varepsilon_{0} d}{e^{2}} u
$$

are used for comparison. Figure 6 shows the individual pair potential energies and the total potential energy, or sum of the pair potentials, as a function of the separation distance between monomer centers, $r^{+}$, along three routes for which the approach axis runs through the centers of the two monomers. The upper figure corresponds to the "parallel" route in which the dimers are aligned antiparallel, the central figure represents a route in which one monomer is tilted $45^{\circ}$ toward the other, and the bottom figure represents the " $\mathrm{T}$ " configuration in which one monomer is perpendicular to the other. As can be seen in Fig. 6, the individual pair Coulombic potentials are relatively large and long range, but the molecule-molecule interaction, given by the sum of the pair potentials, is much smaller and of shorter range. It is of course identically zero for the $\mathrm{T}$ configuration because of the exact cancellation of charge interactions by the symmetry. Because the charge separation in the molecule is small relative to the monomer nonbonded distances, a net cancellation of the point-point interactions occurs making the moleculemolecule interaction of short range. Pair potential landscapes of neutral dimers, even though there are permanent partial charges within the monomers, can thus be effectively represented without point charges as we have done by setting all the partial charges in Eq. (4) to zero. As long as such a representation reproduces the correct energy landscape, as this model does, simulations based on the model will produce the correct fluid properties without the inconvenience of Ewald sums to calculate individual Coulombic interactions.

\section{SUMMARY}

We have calculated $607 \mathrm{CP}$ corrected energies from homogeneous dimers of methanol and ethanol representing 41 different approach routes. These routes provide reasonably comprehensive potential energy surfaces for the dimers. Routes providing opportunity for hydrogen bonding show deep attractive wells, but the dispersion interactions emphasized in other relative monomer orientations are also significant. Much of the qualitative complexity of each potential 

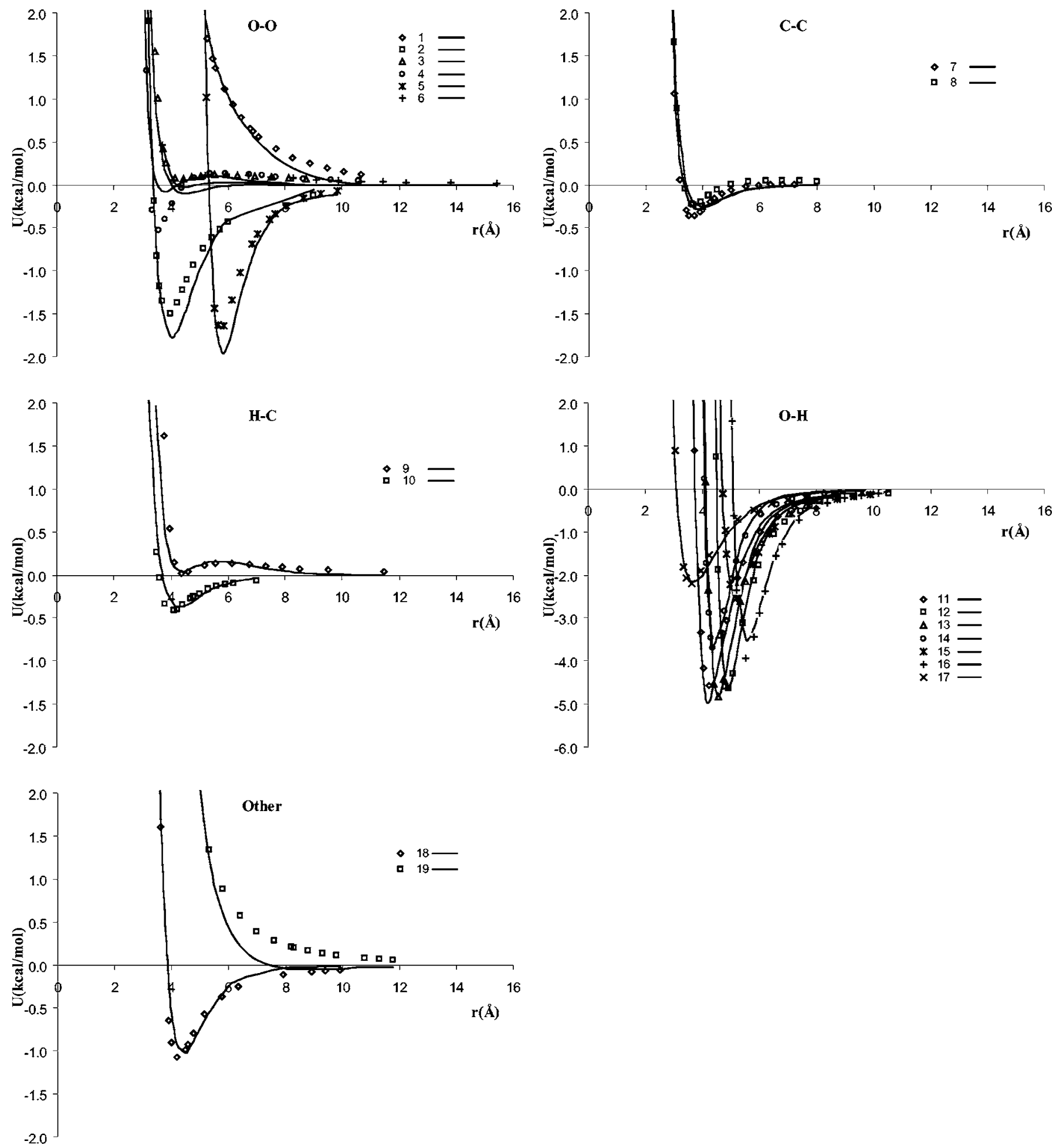

FIG. 5. Dimer energies for methanol as a function of distance between $\mathrm{C}_{\alpha}$ monomer sites from ab initio calculations (points) and from the site-site model without point charges (lines).

energy surface can be understood in terms of the chargedistribution calculated within the rigid monomers. Interesting shoulders arise in the potential surfaces due to competing attractions and repulsions between different sites within the dimer.

These shoulders and other complexities provide a good challenge and validation opportunity for site-site models employing spherical symmetry about atomic centers. We have successfully modeled the $a b$ initio potential energy surfaces using a pairwise-additive, site-site model based on a modified Morse potential for the repulsion-dispersion interactions. The surfaces could be modeled about equally well using either the site-site model to represent the complete interactions or by using a point-charge model for the Coulombic contributions to the potential and the Morse site-site model for the remaining dispersion interactions. Parameters for both models are provided, though the model without charges may provide advantages for some simulations because techniques for 

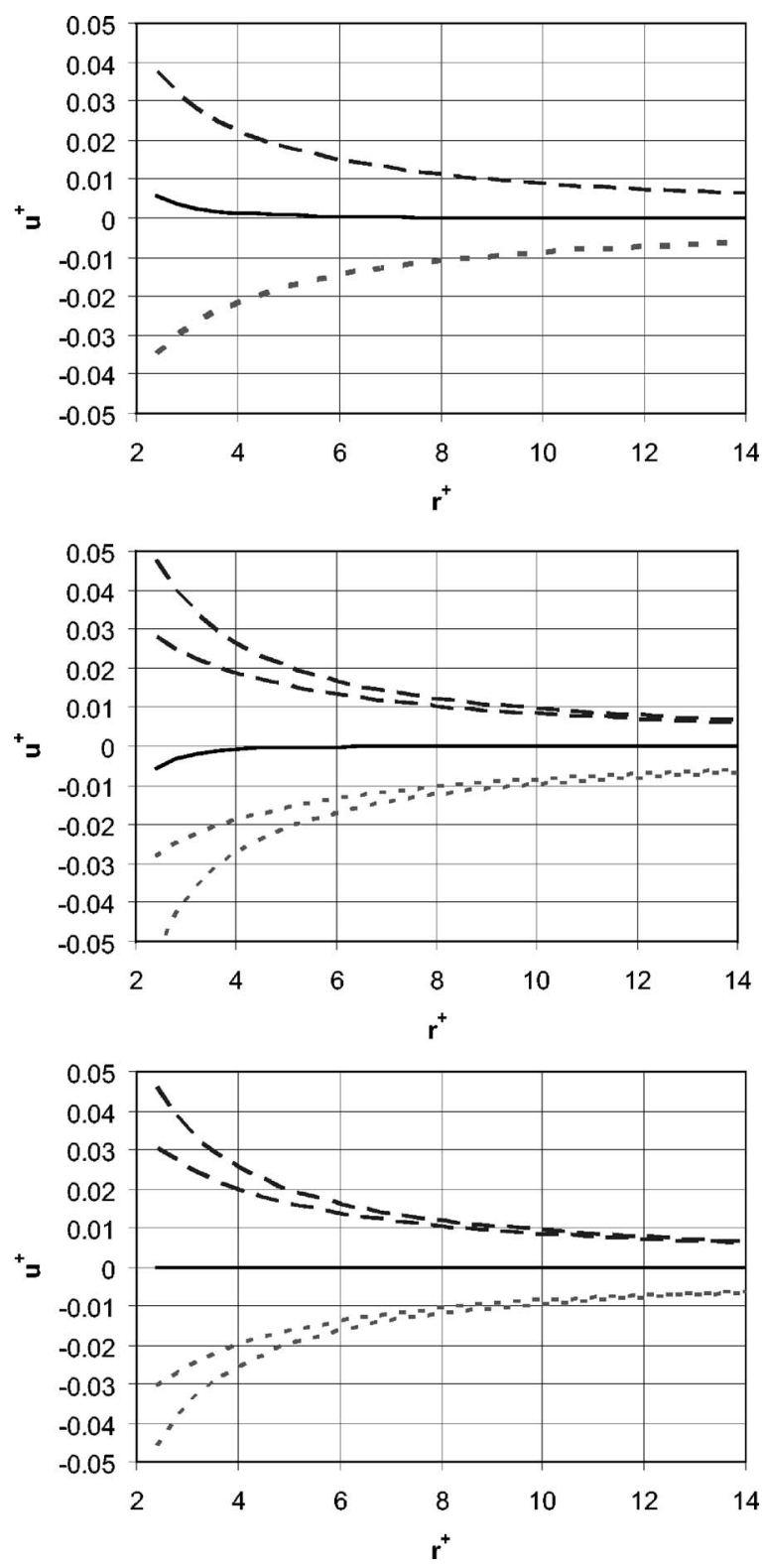

FIG. 6. Calculated dimensionless potential energies for dimers of a model diatomic molecule with atomic site fractional electron charges of \pm 0.3 for the antiparallel dimer configuration (top), $45^{\circ}$ configuration (middle), and the "T" or $90^{\circ}$ configuration (bottom) showing the like pair interactions (dashed lines), the unlike pair interactions (dotted lines), and the sum of the pair interactions (solid lines).

handling long-range interactions are not required between neutral molecules when the charge distribution is not modeled with pointwise interactions.

${ }^{1}$ A. van der Avoird, P. E. S. Wormer, and R. Moszynski, Chem. Rev. (Washington, D.C.) 94, 1931 (1994).

${ }^{2}$ R. L. Rowley and T. Pakkanen, J. Chem. Phys. 110, 3368 (1999).

${ }^{3}$ A. J. Stone, The Theory of Intermolecular Forces (Oxford University Press, Oxford, 1996).

${ }^{4}$ M. Marques and E. Gross, Annu. Rev. Phys. Chem. 55, 427 (2004).

${ }^{5}$ A. H. Li and S. D. Chao, J. Chem. Phys. 125, 094312 (2006).

${ }^{6}$ D. E. Woon, J. Chem. Phys. 100, 2838 (1994).

${ }^{7}$ P. Slavicek, R. Kalus, P. Paska, I. Odvarkova, P. Hobza, and A. Malijevsky, J. Chem. Phys. 119, 2102 (2003).

${ }^{8}$ A. Ruzsinszky, J. P. Perdew, and G. I. Csonka, J. Phys. Chem. A 109, 11015 (2005).
${ }^{9}$ V. F. Lotrich, R. J. Bartlett, and I. Grabowski, Chem. Phys. Lett. 405, 43 (2005)

${ }^{10}$ A. E. Nasrabad, R. Laghaei, and U. K. Deiters, J. Chem. Phys. 121, 6423 (2004).

${ }^{11}$ K. Patkowski, G. Murdachaew, C.-M. Fou, and K. Szalewicz, Mol. Phys. 103, 2031 (2005).

${ }^{12}$ G. Vayner, Y. Alexeev, J. Wang, T. L. Windus, and W. L. Hase, J. Phys. Chem. A 110, 3174 (2006).

${ }^{13}$ Y. Zhou and D. Xie, J. Chem. Phys. 120, 8575 (2004); 121, 2630 (2004); 122, 174312 (2005); 122, 234312 (2005); 123, 134323 (2005).

${ }^{14}$ J. Zhu, Y.-P. Lu, X.-R. Chen, and Y. Cheng, Eur. Phys. J. D 33, 43 (2005)

${ }^{15}$ J.-X. Chen, H. Zhu, D.-Q. Xie, and G.-S. Yan, Huaxue Xuebao 62, 5 (2004).

${ }^{16}$ G. Murdachaew, K. Szalewicz, H. Jiang, and Z. Bacic, J. Chem. Phys. 121, 11839 (2004)

${ }^{17}$ B. J. Anderson, J. W. Tester, and B. L. Trout, J. Phys. Chem. B 108, 18705 (2004)

${ }^{18}$ R. Hernandez-Lamoneda, M. Bartolomei, and M. I. Hernandez, J. Phys. Chem. A 109, 11587 (2005).

${ }^{19}$ M. H. K. Jafari, A. Maghari, and S. Shahbazian, Chem. Phys. 314, 249 (2005).

${ }^{20} \mathrm{~S}$. Tsuzuki and K. Tanabe, J. Phys. Chem. 95, 2272 (1991).

${ }^{21}$ D. E. Williams and D. J. Craycroft, J. Chem. Phys. 91, 6365 (1987).

${ }^{22}$ J. J. Novoa, M.-H. Whangho, and J. M. Williams, J. Chem. Phys. 94, 4835 (1991).

${ }^{23}$ S. Tsuzuki, T. Uchinaru, K. Tanabe, and S. Kuwajima, J. Chem. Phys. 98, 1830 (1994).

${ }^{24}$ S. Tsuzuki and H. P. Luthi, J. Chem. Phys. 114, 3949 (2001).

${ }^{25}$ S. Tsuzuki, K. Honda, T. Uchimaru, and M. Mikami, J. Chem. Phys. 124, 114304 (2006).

${ }^{26}$ S. Tsuzuki, T. Uchimaru, M. Mikami, and K. Tanabe, J. Phys. Chem. A 102, 2091 (1998); Chem. Phys. Lett. 252, 206 (1996).

${ }^{27}$ S. Tsuzuki, T. Uchimaru, and K. Tanabe, Chem. Phys. Lett. 287, 202 (1998).

${ }^{28}$ S. Tsuzuki, K. Honda, T. Uchimaru, and M. Mikami, J. Phys. Chem. A 108, 10311 (2004).

${ }^{29}$ K. Shuler and C. E. Dykstra, J. Phys. Chem. A 104, 4562 (2000).

${ }^{30} \mathrm{~S}$. Tsuzuki, K. Honda, T. Uchimaru, M. Mikami, and K. Tanabe, J. Am. Chem. Soc. 122, 3746 (2000).

${ }^{31}$ S. Tsuzuki, K. Honda, T. Uchimaru, and M. Mikami, J. Chem. Phys. 124, 114304 (2006).

${ }^{32}$ J.-P. Jalkanen, T. A. Pakkanen, and R. L. Rowley, J. Chem. Phys. 120, 1705 (2004).

${ }^{33}$ J.-P. Jalkanen, T. A. Pakkanen, Y. Yang, and R. L. Rowley, J. Chem. Phys. 118, 5474 (2003).

${ }^{34}$ R. L. Rowley, Y. Yang, and T. A. Pakkanen, J. Chem. Phys. 114, 6058 (2001).

${ }^{35}$ J.-P. Jalkanen, R. Mahlanen, T. A. Pakkanen, and R. L. Rowley, J. Chem. Phys. 116, 1303 (2002).

${ }^{36}$ R. Mahlanen, J.-P. Jalkanen, and T. A. Pakkanen, Chem. Phys. 313, 271 (2005).

${ }^{37}$ S. Tsuzuki, T. Uchimaru, and M. Mikami, J. Phys. Chem. A 110, 2027 (2006).

${ }^{38}$ S. Tsuzuki, T. Uchimaru, M. Mikami, and S. Urata, J. Chem. Phys. 121, 9917 (2004); J. Phys. Chem. A 107, 7962 (2003).

${ }^{39}$ J. Li, F. Zhao, and F. Jing, J. Comput. Chem. 24, 345 (2003).

${ }^{40}$ H.-J. Song, H.-M. Xiao, H.-S. Dong, Y.-G. Huang, X.-P. Long, and Y.-P. Tang, Chin. J. Chem. 22, 1377 (2004).

${ }^{41}$ S. Roszak, R. H. Gee, K. Balasubramanian, and L. E. Fried, J. Chem. Phys. 123, 144702 (2005).

${ }^{42}$ J. Dong, J. Zhu, X. Chen, G. Chen, F. Zhang, X. Cheng, and Y. Lu, Ziran Kexueban 41, 1212 (2004).

${ }^{43}$ S. J. Grabowski and J. Leszczynski, J. Phys. Chem. A 109, 6397 (2005).

${ }^{44}$ W. T. M. Mooij, F. B. van Duijneveldt, J. G. C. M. van Duijneveldt-van de Rijdt, and B. P. van Eijck, J. Phys. Chem. A 103, 9872 (1999).

${ }^{45}$ J. M. Hermida-Ramon and M. A. Rios, J. Phys. Chem. A 102, 2594 (1998).

${ }^{46}$ G. C. Groenenboom, E. M. Mas, R. Bukowski, K. Szalewicz, P. E. S. Wormer, and A. van der Avoird, Phys. Rev. Lett. 84, 4072 (2000).

${ }^{47}$ I. Adamovic, H. Li, M. H. Lamm, and M. S. Gordon, J. Phys. Chem. A 110, 519 (2006).

${ }^{48}$ Y. Kita, K. Wako, I. Okada, and M. Tachikawa, J. Chem. Theory Comput. 4, 49 (2005). 
${ }^{49}$ S. Tsuzuki, K. Honda, T. Uchimaru, and M. Masuhiro, J. Chem. Phys. 120, 647 (2004); 122, 144323 (2005).

${ }^{50}$ K. Thirumoorthy and N. Nandi, J. Phys. Chem. B 110, 8840 (2006).

${ }^{51}$ S. M. Cybulski and C. E. Seversen, J. Chem. Phys. 122, 014117 (2005).

${ }^{52}$ G. Prampolini, J. Chem. Theory Comput. 2, 556 (2006).

${ }^{53}$ N. K. Lee and S. K. Kim, J. Chem. Phys. 122, 031102 (2005).

${ }^{54}$ S. L. Garrison and S. I. Sandler, J. Phys. Chem. B 108, 18972 (2004).

${ }^{55}$ R. H. Gee, S. Roszak, K. Balasubramanian, and L. E. Fried, J. Chem. Phys. 120, 7059 (2004).
${ }^{56}$ J. M. Hayes, J. C. Greer, and D. A. Morton-Blake, J. Comput. Chem. 25, $1953(2004)$

${ }^{57}$ Y. Sakiyama, S. Takagi, and Y. Matsumoto, J. Chem. Phys. 122, 234501 (2005).

${ }^{58}$ I. Cacelli, G. Cinacchi, G. Prampolini, and A. Tani, J. Am. Chem. Soc. 126, 14278 (2004).

${ }^{59}$ M. Z. Hernandes and R. L. Longo, J. Mol. Model. 11, 61 (2005).

${ }^{60}$ M. J. Frisch, G. W. Trucks, H. B. Schlegel et al., GAUSSIAN 98, Revision A.6, Gaussian, Inc., Pittsburgh, PA, 1998.

${ }^{61}$ J.-P. Jalkanen, S. Pulkkinen, T. A. Pakkanen, and R. L. Rowley, J. Phys. Chem. A 109, 2866 (2005). 